\title{
Let Us Learn From Our Mistakes
}

\section{K.C. S.}

The medical profession is considered a noble profession worldwide because it helps in preserving life. Doctors are often figured next to God by large populations in the developing world. Though a doctor may not be in a position to save a patient's life at all times, he or she is expected to use his or her almost-divine knowledge and skill in the most appropriate manner in the interest of the patient who has entrusted his or her life to the treating doctor. Therefore, it is expected that a doctor will do no harm to a patient who has handed over his or her body and soul with the hope that the patient will have a good quality of life after the treatment.

Negligence is defined as the omission by a health care provider that deviates from the accepted standard of practice in the medical community that causes injury to the patient. ${ }^{1}$ So, medical negligence is said to occur when a doctor or any other medical professional (dentist, nurse, medical attendant) performs his or her job in a way that deviates from the globally-accepted medical standard of care. If a doctor breaks the rules regarding how to treat a patient and does something that is against the general rules, then that doctor has failed to perform his or her duty. This then becomes a case of medical negligence. However, medical negligence may not always result in injury to the patient. On the contrary, the death of a patient while undergoing treatment or surgery does not necessarily mean medical negligence has occured. Error of judgment, failure in making a proper diagnosis or failure to cure a disease is not always a medical negligence. Like it or not, doctors and patients both have played leading roles in the history of medical negligence. When a patient does not give a proper medical history, the doctor can't be blamed for the consequences.

Medical negligence can occur in an infinite number of ways, but most instances of medical negligence can be grouped into one of the following categories. ${ }^{2}$

Misdiagnosis

Failure to diagnose at the right time

Surgical or procedural error

Failure to follow-up with treatment

Failure to treat on time

Medication or prescription error

In this issue, a short communication on medical negligence by Kumar L and Batista BK has been published. ${ }^{3}$ It gives a clear picture of the different aspects of medical negligence. Since Nepal and India share many things in common, this article would be very good reading for readers of both countries.

Sometimes the newspapers are flooded by the news that a surgery planned for one patient was performed on another. Or that a patient planned for one type of surgery undergoes another type of surgery. Wrong site surgery is also a form of medical negligence. Patients who would have otherwise lived normal lives are then bound to live with the tragic consequences of such medical negligence for the rest of their lives. To err is human. We need to learn from our mistakes. When we make any mistakes, we have to find the reasons that led to our mistakes and then look forward and learn from such mistakes. 
I personally believe that mistakes are lessons of wisdom. The past cannot be changed. However, the future is yet in our power. And learning from our mistakes must mean that we do not repeat them again.

Dr. Sudhamshu K.C.

Liver Unit, National Academy of Medical Sciences

Mahabouddha, Kathmandu, Nepal

e-mail: Sudhamshu.liver@gmail.com

\section{REFERENCES}

1. Denning Lord MR. The Discipline of Law. New Delhi; Aditya Books Private Limited: 1993

2. http://www.medicalmalpractice.com/resources/medical-malpractice/medical-malpracticeintroduction/medical-negligence.htm

3. Kumar L and Batista BK. Medical negligence- Meaning and Scope in India. JNMA vol 51 no. 1 issue 181, jan-march 2011 